\title{
Causes and Secondary Prevention of Acute Ischemic Stroke in Adults
}

\author{
Märit Jensen ${ }^{1}$ Götz Thomalla ${ }^{1}$ \\ ${ }^{1}$ Klinik und Poliklinik für Neurologie, Kopf- und Neurozentrum, \\ Universitätsklinikum Hamburg-Eppendorf, Hamburg, Germany \\ Hämostaseologie 2020;40:22-30.
Address for correspondence Götz Thomalla, Klinik und Poliklinik für Neurologie, Kopf- und Neurozentrum, Universitätsklinikum Hamburg- Eppendorf, Martinistr. 52, Hamburg, D-20246, Germany \\ (e-mail: thomalla@uke.de).
}

\begin{abstract}
Keywords

- ischemic stroke

- etiology

- secondary prevention

Zusammenfassung

\section{Schlüsselwörter \\ - ischämischer Schlaganfall \\ - Schlaganfallursachen \\ - Sekundärprophylaxe}

Stroke still remains a major cause of death and disability worldwide. Ischemic stroke is the most common type of stroke. Causes of ischemic stroke can be classified into large-artery atherosclerosis, cardiogenic embolism, small-vessel disease, stroke of other determined etiology, and stroke of undetermined etiology. Stroke causes in adults are mainly attributable to classical cardiovascular risk factors such as hypertension, diabetes, hypercholesterolemia, and smoking. In neuroimaging, stroke subtypes can be defined according to lesion localization and distribution (territorial infarct, lacunar infarct, hemodynamic infarct), which provide information as to the underlying etiology. Acute stroke management comprises rapid neurological assessment and rapid imaging to initiate effective reperfusion treatment with intravenous thrombolysis and mechanical thrombectomy. Stroke survivors are at increased risk of recurrent stroke. Therefore, diagnosis of the underlying cause and optimal secondary prevention is of importance. Pharmacologic secondary prevention includes antithrombotic therapy with antiplatelet drugs, oral anticoagulation, and treatment of vascular risk factors. Nonpharmacologic measures of secondary prevention comprise surgical or interventional revascularization of symptomatic carotid stenosis and interventional closure of patent foramen ovale.

Der Schlaganfall beim Erwachsenen stellt weiterhin weltweit eine der häufigsten Ursachen für Tod und Behinderung dar. Der ischämische Schlaganfall ist die häufigste Unterform und kann verschiedenen Ursachen zugeordnet werden: Makroangiopathie, kardiale Embolie, Mikroangiopathie, andere Ätiologie und unbekannte Ätiologie. Die zuvor beschriebenen Ursachen sind assoziiert mit den klassischen kardiovaskulären Risikofaktoren arterielle Hypertonie, Diabetes mellitus, Hypercholesterinämie und Rauchen. In der zerebralen Bildgebung lassen sich Schlaganfallläsionen nach Lokalisation und Verteilungen klassifizieren (territorial, lakunär, hämodynamisch), welche Hinweise auf die zugrundeliegende Ätiologie geben können. Die Akuttherapie des Schlaganfalls umfasst neben der schnellen neurologischen Untersuchung die rasche Bildgebung, um nach Ausschluss einer Blutung die weitere Akuttherapie mittels intravenöser Thrombolyse und mechanischer Rekanalisation einzuleiten. Entscheidend für die Vermeidung eines erneuten Schlaganfalls ist die umfassende Ursachendiagnostik als Basis für eine effektive Sekundärprophylaxe. Zur medikamentösen Sekundärprophylaxe zählen in erster Linie die Thrombozytenaggregationshemmung, die orale Antikoagulation und die Behandlung der kardiovaskulären Risikofaktoren. Darüber hinaus kommen als nicht-medikamentöse Maßnahmen der Sekundärprophylaxe die operative oder interventionelle Revaskularisierung einer symptomatischen Carotisstenose und der Verschluss eines persistierenden Foramen ovale in Frage.
\end{abstract}

received

August 5, 2019

accepted after revision

September 10, 2019 (c) 2020 Georg Thieme Verlag KG Stuttgart · New York
DOI https://doi.org/

10.1055/s-0039-1700502. ISSN 0720-9355. 


\section{Introduction}

Stroke remains one of the leading causes of death and disability worldwide. ${ }^{1}$ Due to ongoing demographic changes including aging of the population, its significance on a societal level is likely to increase over the next few years.

There are two main types of stroke: ischemic and hemorrhagic strokes. Ischemic strokes are more frequent and caused by a disruption of blood supply to certain brain regions leading to a lack of oxygen and subsequent loss of function and death of brain tissue. Depending on the location of affected brain areas, manifold clinical manifestations are possible.

The causes of ischemic stroke include thromboembolic, atherothrombotic, microangiopathic, and hemodynamic mechanisms. Stroke survivors are at increased risk of a recurrent stroke. Effective secondary prevention includes antiplatelet therapy, anticoagulation, and control of causal risk factors, and should be targeted to the underlying mechanism.

This review will focus on ischemic stroke in adults. Causes of stroke are largely attributable to age-dependent cardiovascular diseases and risk factors, and treatment of these risk factors is crucial in secondary prevention. In younger stroke patients ( $<45$ years), the proportion of patients with other rare causes is higher than in the total stroke population. Therefore, these patients need specific attention and diagnostic evaluation.

\section{Epidemiology}

In 2016, the incidence of stroke worldwide was 13.7 million, and 5.5 million people died from stroke. ${ }^{1}$ Based on these data, stroke was the second largest cause of death globally after ischemic heart disease. Fewer women than men died as a result of stroke. Of the 13.7 million new strokes each year, over 9.5 million (69.9\%) were ischemic strokes. In total, 2.7 million people died from ischemic stroke and there were 51.9 million disability-adjusted life years due to ischemic stroke. ${ }^{1}$ High age is a significant risk factor for the occurrence of strokes. In Germany, the mean age of stroke patients in 2012 was 72.5 years. $^{2}$ The observation is mainly attributable to higher prevalence of cardiovascular risk factors with increasing age.

\section{Types of Brain Infarction}

\section{Territorial Infarct}

Occlusion of a larger brain artery causes a territorial infarction, i.e., the death of the brain tissue supplied by the occluded artery. In most cases, such infarctions are caused by thromboembolism with thrombi stemming from larger upstream arteries, e.g., the carotid artery, or the heart. Occlusion resulting from local atherothrombosis, comparable to the mechanism of occlusion of coronary arteries leading to myocardial infarction, is much less common in the brain but may occur, e.g., in the presence of pre-existing intracranial stenosis. The middle cerebral artery territory is the most commonly affected territory due to the direct flow from the internal carotid artery ( - Fig. 1A, B). Patients with territorial kinds of infarcts often present with severe neurological syndromes.

\section{Lacunar Infarct}

Lacunar infarcts are small $(<15 \mathrm{~mm})$ noncortical infarcts (-Fig. 1C). They are most commonly located in the deep nuclei of the brain (putamen, thalamus, and caudate) as well as the pons or the posterior limb of the internal capsule. Lacunar infarcts are a typical imaging hallmark of cerebral small-vessel disease (SVD; see below). With regard to the underlying pathology, it is assumed that lacunar strokes are mostly caused by an occlusion of small penetrating arteries due to lipohyalinosis and microatheroma, ${ }^{3}$ which is in line with the high prevalence of risk factors such as arterial hypertension and diabetes mellitus in these patients. However, thromboembolism might also be a cause of occlusion of small penetrating arteries resulting in lacunar infarction, and patients with lacunar infarcts benefit from intravenous thrombolysis as well as patients with other stroke types. ${ }^{4}$

\section{Hemodynamic Infarct}

A hemodynamic stroke is a rare cause of stroke attributable to hypoperfusion of the brain ( - Fig. 1D). Hypoperfusion can be caused by severe local obstruction of an artery, such as carotid or vertebral stenosis, or by a systemic disease such as heart failure or cardiac arrest, or by the combination of both. The difference between hemodynamic strokes from other stroke subtypes is that ischemia occurs in an area of the brain that is at a distance from the blocked vessel. The clinical presentation of these patients often does not differ from those with other stroke subtypes. However, it is important that there might be precipitating circumstances of symptoms, e.g., orthostasis, hypotension, or cardiac arrhythmia.

\section{Transient Ischemic Attack}

A transient ischemic attack (TIA) is a brief episode of neurological symptoms caused by a focal cerebral ischemia. Therefore, a TIA and an ischemic stroke share the same underlying mechanisms; however, a TIA is not associated with permanent cerebral infarction. The definition of TIA is not consistent. Historically, TIA was defined solely based on the duration of symptoms (i.e., <24 hours), while more recently a "tissuebased" definition was suggested (i.e., transient symptoms with no evidence of infarction on imaging). ${ }^{5}$ Due to the high risk of following stroke, a TIA needs equal diagnostic and secondary prevention as ischemic stroke with persistent symptoms.

\section{Causes of Ischemic Stroke}

The identification of the etiology of ischemic stroke is important to guide effective treatment and secondary prevention. Clinical presentation and appearance of lesions on brain imaging may already provide a clue to the underlying etiology (see types of brain infarction). A comprehensive diagnostic work-up is required to identify the underlying cause of stroke and vascular risk factors. Various classifications for ischemic stroke with regard to etiology are available. Most commonly used is the TOAST classification ${ }^{6}$ which denotes five subtypes of ischemic stroke: (1) large-artery atherosclerosis (LAA), (2) cardiogenic embolism, (3) SVD, (4) stroke of other determined etiology, and (5) stroke of undetermined etiology (-Fig. 2). 


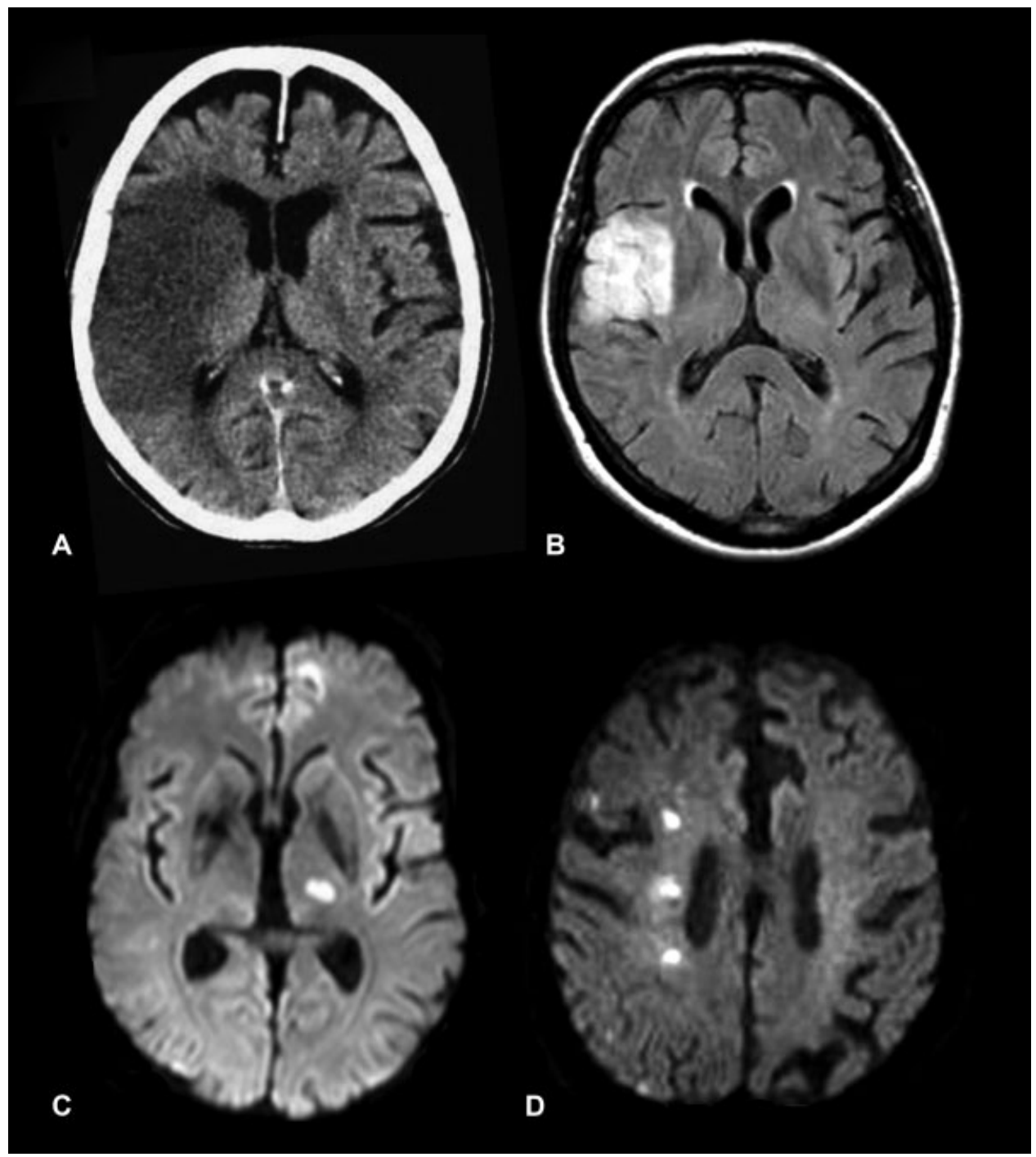

Fig. 1 Most common types of brain infarction based on imaging classification. (A) Territorial right middle cerebral artery (MCA) infarct on CTscan, (B) territorial right MCA infarct on fluid-attenuated inversion recovery (FLAIR) MRI, (C) acute lacunar infarct on diffusion-weighted MRI, and (D) acute hemodynamic right-sided infarcts on diffusion-weighted MRI.

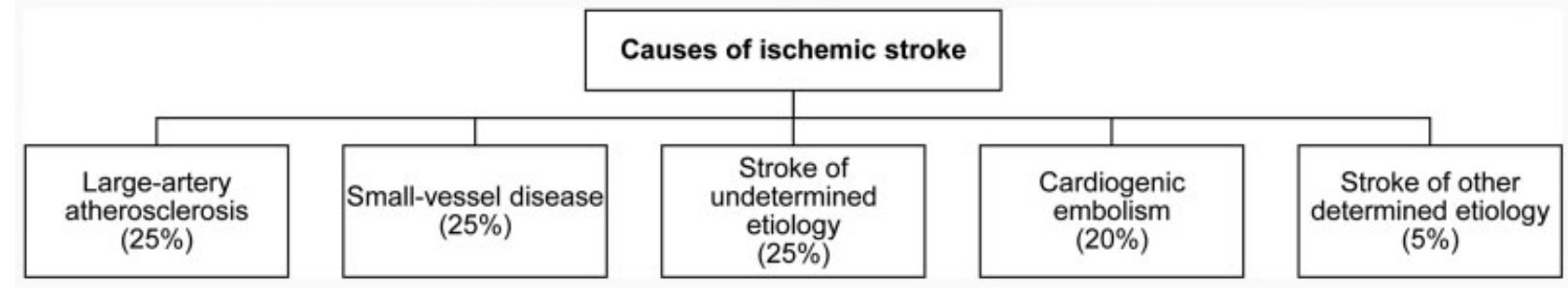

Fig. 2 Causes and distribution of ischemic stroke subtypes. (Modified from Hart RG, Diener HC, Coutts SB, et al. Embolic strokes of undetermined source: the case for a new clinical construct. Lancet Neurol. 2014;13(4):429-438.)

\section{Large-Artery Atherosclerosis}

LAA of intracranial or extracranial arteries is responsible for approximately $25 \%$ of all ischemic strokes. There are multiple factors contributing to the pathogenesis of atherosclerosis including inflammation, endothelial dysfunction, and classical cardiovascular risk factors such as hypertension, diabetes, hypercholesterolemia, and smoking. Strokes due to LAA are commonly caused by an artery-to-artery embolism or, less common, vessel stenosis resulting in hemodynamic infarc- tions. On neuroimaging, these strokes then present with a territorial or hemodynamic distribution pattern.

\section{Cardiogenic Embolism}

Cardiogenic embolism accounts for approximately 20\% of ischemic strokes. A cardiogenic embolism results from a cardiac blood clot that enters the bloodstream and subsequently occludes a cerebral artery. The most frequent cause is atrial fibrillation (AF) with blood clots typically formed in the 
left atrial appendage. Moreover, heart failure, patent foramen ovale (PFO), or prosthetic heart valves are risk factors for cardioembolic strokes. It has been shown that cardiogenic embolism causes more severe strokes than other ischemic stroke subtypes. ${ }^{7}$ On imaging, cardioembolic strokes usually present as territorial infarcts and may occur in more than one arterial territory and even bilaterally.

\section{Small-Vessel Disease}

Cerebral SVD is one of the three most common causes of ischemic stroke responsible for approximately $25 \%$ of ischemic strokes. SVD is a term used to describe a pathology affecting the microvasculature of the brain. Mainly two microvascular pathologies are described: lipohyalinosis of the small perforating arteries feeding deep subcortical structures, and microatheroma formation at the origin of penetrating arteries from major cerebral arteries. Frequent locations for SVD include the basal ganglia, the corona radiata, the internal capsule, the pons, and the thalamus. ${ }^{8}$ Infarctions due to SVD are typically small lacunar infarcts and might account for the so-called lacunar syndromes. Historically, several these lacunar syndromes have been described, the most common ones being pure motor stroke, pure sensory stroke, ataxic hemiparesis, sensorimotor stroke, and dysarthria-clumsy hand syndrome. However, these syndromes can as well result from different stroke types, e.g., small embolic strokes.

\section{Stroke of Other Determined Etiology}

Stroke of other determined etiology includes, amongst others, extracranial or intracranial arterial dissections, stroke caused by vasculitis, coagulation disorders, or hematological diseases. An overview of the most frequent "other etiologies" is given in -Table 1. Especially in the case of a stroke at a young age without classical risk factors, these etiologies should be considered and specific diagnostic tests should be initiated.

\section{Stroke of Undetermined Etiology}

Finally, in a relevant proportion of ischemic stroke, no specific etiology can be determined. Strokes of undetermined etiology, also known as cryptogenic strokes, are thought to comprise up to $25 \%$ of all ischemic strokes, with a higher proportion in younger stroke populations. This includes patients in whom a complete workup screening for cardiac causes, intracranial or extracranial artery stenosis, and other rare determined causes has been unrevealing. However, there is plausible evidence that most cryptogenic strokes are likely to be of thromboembolic origin. Therefore, the clinical construct of "embolic stroke of undetermined source" (ESUS) was established to identify patients with nonlacunar cryptogenic ischemic strokes in whom embolism was the likely stroke mechanism to guide randomized controlled trials of oral anticoagulation (OAC) in these patients. ${ }^{9}$

\section{Diagnosis and Acute Treatment}

Acute diagnosis of stroke comprises rapid physical examination, recording of vital parameters and basal laboratory parameters, and rapid brain imaging using either computed
Table 1 Overview of strokes caused by other determined etiology

\begin{tabular}{|c|}
\hline Cause \\
\hline $\begin{array}{l}\text { Dissection of cerebral arteries } \\
\text { - Spontaneous dissection of the cervical carotid artery or } \\
\text { vertebral artery } \\
\text { - Spontaneous dissection of intracranial arteries } \\
\text { - Dissection in the context of connective tissue diseases } \\
\text { (e.g., Ehlers-Danlos syndrome, Marfan syndrome, } \\
\text { Loeys-Dietz syndrome, fibromuscular dysplasia) }\end{array}$ \\
\hline $\begin{array}{l}\text { Vasculitis } \\
\text { - Primary angiitis of the central nervous system (PACNS) } \\
\text { - Systemic vasculitis/vasculopathy (e.g., Takayasu arteri- } \\
\text { tis, cranial arteritis, lupus erythematosus, panarteritis } \\
\text { nodosa, granulomatosis with polyangiitis, ANCA-asso- } \\
\text { ciated vasculitis, Churg-Strauss syndrome, cryoglobuli- } \\
\text { nemia, Henoch-Schönlein purpura, sarcoidosis, M. } \\
\text { Behçet, Sjögren syndrome, microscopic polyangiitis) } \\
\text { - Infectious/parainfectious vasculitis (lues, hepatitis B/C, } \\
\text { HIV, CMV, VZV, tuberculosis, bacterial/viral meningitis) }\end{array}$ \\
\hline $\begin{array}{l}\text { Coagulation disorders } \\
\text { - Antithrombin deficiency } \\
\text { - Protein C deficiency, protein S deficiency } \\
\text { - Factor V Leiden mutation } \\
\text { - Prothrombin gene mutation } \\
\text { - Antiphospholipid syndrome (APS) } \\
\text { - Paraneoplastic coagulation disorders }\end{array}$ \\
\hline $\begin{array}{l}\text { Hematological diseases } \\
\text { - Sickle cell anemia } \\
\text { - Thalassemia } \\
\text { - Polycythemia vera } \\
\text { - Essential thrombocythemia } \\
\text { - Thrombotic thrombocytopenic purpura (TTP) } \\
\text { - Intravascular lymphoma } \\
\text { - Paroxysmal nocturnal hemoglobinuria }\end{array}$ \\
\hline $\begin{array}{l}\text { Cardiac causes } \\
\text { - Endocarditis } \\
\text { - Patent foramen ovale (PFO) } \\
\text { - Cardiomyopathy } \\
\text { - Congenital heart defects (atrial septal defect, ventricular } \\
\text { septal defect, valve defect) } \\
\text { - Atrial myxoma }\end{array}$ \\
\hline $\begin{array}{l}\text { Hereditary diseases } \\
\text { - CADASIL } \\
\text { - MELAS } \\
\text { - Fabry's disease }\end{array}$ \\
\hline $\begin{array}{l}\text { Infections } \\
\text { - Parainfectious }\end{array}$ \\
\hline
\end{tabular}

Medicines and drugs

- Heparin-induced thrombocytopenia (HIT)

- Hormonal contraception

- Cocaine, amphetamines, heroin

Moyamoya disease

Susac syndrome

\begin{tabular}{l} 
Migraine \\
\hline Colitis ulcerosa \\
\hline Pregnancy \\
- Eclampsia, preeclampsia, coagulation disorders in \\
pregnancy
\end{tabular}

Abbreviations: ANCA, antineutrophil cytoplasmic antibody; CMV, cytomegalovirus; HIV, human immunodeficiency virus; VZV, varicella-zoster virus. 
Table 2 Standard diagnostic measures for ischemic stroke in adults

\begin{tabular}{|l|l|}
\hline Diagnostic measures & Parameters, pathological findings \\
\hline Brain imaging (CT or MRI) & $\begin{array}{l}\text { - Detection/exclusion of intracerebral bleeding } \\
\text { - Localization of ischemic infarcts } \\
\text { - Demarcated cerebral infarcts } \\
\text { - "DWI-FLAIR mismatch," "penumbral imaging” (“wake-up stroke”) }\end{array}$ \\
\hline CT angiography or MR angiography & $\begin{array}{l}\text { - Detection of occlusions or stenosis of large-sized and medium-sized arteries } \\
\text { in atherosclerosis } \\
\text { - Dissections }\end{array}$ \\
\hline $\begin{array}{l}\text { Ultrasound examination of extracranial } \\
\text { and intracranial arteries }\end{array}$ & $\begin{array}{l}\text { - Detection of large-artery atherosclerosis } \\
\text { - Dissections }\end{array}$ \\
\hline ECG, long-time ECG & - Detection of cardiac arrhythmias \\
\hline Echocardiography & - Heart failure, valvular deficiency, patent foramen ovale (PFO) \\
\hline Laboratory tests & - Assessment of hematological diseases, liver dysfunction or kidney dysfunction, \\
\hline Blood pressure monitoring & - Arterial hypertension \\
\hline
\end{tabular}

Abbreviations: CT, computed tomography; ECG, electrocardiography; MR, magnetic resonance.

tomography (CT) or magnetic resonance imaging (MRI). After exclusion of intracerebral bleeding, intravenous thrombolysis can be performed within 4.5 hours after the onset of symptoms or based on findings of advanced brain imaging by either MRI or perfusion CT using "DWI-FLAIR mismatch" or "penumbral imaging" if the onset of symptoms is beyond 4.5 hours or unknown ("wake-up stroke"). ${ }^{10,11}$ Subsequently, or primarily, if thrombolysis is contraindicated, mechanical recanalization should be performed in patients with large-vessel occlusions. ${ }^{12}$

The subacute assessment of patients who have suffered a stroke mainly aims to determine the precise etiology so as to guide effective secondary prevention. Standard diagnostic measures include ultrasound examination of extracranial and intracranial arteries, cardiac diagnostic using electrocardiography (ECG), long-term ECG (for at least 24 hours), and echocardiography, and systematic screening for cardiovascular risk factors such as blood pressure monitoring and laboratory parameters (e.g., blood glucose, cholesterol; see - Table 2). Of course, other cardiovascular risk factors such as smoking and family history should be evaluated as well. In most cases of stroke in adults with a vascular risk profile, these diagnostic procedures lead to an etiological classification. If not, specific examinations should be added (e.g., specific laboratory tests or lumbar puncture for vasculitis screening).

\section{Secondary Prevention}

Secondary prevention of stroke includes strategies to reduce the risk of stroke recurrence among patients who had previously presented with a stroke or TIA. Management strategies, which should be specific to the underlying etiology, include the use of antiplatelet or anticoagulant drugs, risk factor modification, carotid surgery, and carotid artery stenting.

\section{Antiplatelet Therapy}

Antiplatelet therapy is the basis of secondary prevention for noncardioembolic ischemic stroke or TIA. There are different types of approved antiplatelet drugs in Germany which include aspirin monotherapy, the combination of aspirin and dipyridamole, and thienopyridines (clopidogrel and ticlopidine). Ticlopidine is associated with an increased risk of neutropenia and therefore not generally used in clinical practice. As of today, there is no evidence of a benefit of antiplatelet treatment with prasugrel or ticagrelor, and prasugrel is formally contraindicated with recent stroke. The Antithrombotic Trialists' collaboration meta-analysis of secondary preventive antiplatelet therapy showed a relative risk reduction for the combined endpoint stroke, myocardial infarction, and death of approximately $22 \%{ }^{13}$ Antiplatelet therapy should be initiated within 24 hours of admission and continued lifelong.

The most commonly used antiplatelet agent is aspirin. Aspirin is a cyclooxygenase inhibitor that blocks the formation of thromboxane $\mathrm{A} 2$ and therefore reduces platelet aggregation. Aspirin lowers the risk of stroke by approximately $15 \%$ and the preventive effect is given across doses from 50 and $1,500 \mathrm{mg} / \mathrm{d} .{ }^{14}$ By contrast, bleeding complications and gastrointestinal side effects are dose-dependent and their frequency significantly increased with higher doses of aspirin. ${ }^{15}$ Currently, $100 \mathrm{mg}$ aspirin per day is recommended in Germany as well as in most European countries.

As an alternative to aspirin, the thienopyridine clopidogrel is used in clinical practice. Thienopyridines are adenosine diphosphate (ADP) receptor blockers that inhibit platelet activation and aggregation induced by ADP. Clopidogrel was compared with aspirin in the CAPRIE trial. ${ }^{16}$ Patients with stroke, myocardial infarction, or peripheral vascular disease were randomized to aspirin $325 \mathrm{mg} / \mathrm{d}$ or clopidogrel $75 \mathrm{mg} / \mathrm{d}$. The results indicate that clopidogrel is more effective than aspirin in reducing the combined risk of ischemic stroke, myocardial infarction, or vascular death in patients with atherosclerotic vascular disease. However, in a subgroup analysis of patients with previous stroke, the difference in relative-risk reduction between clopidogrel and aspirin was not statistically significant. The incidence of side effects among both groups was comparable, with a slightly higher rate of gastrointestinal bleeding in patients who 
received aspirin. It has to be considered that the action of clopidogrel is dependent on variable genetically determined metabolic activation. Therefore, in some cases treatment failure might occur.

The combination of aspirin and dipyridamole is no longer used in clinical practice. Therefore, a detailed description is not part of this review.

Nevertheless, the benefit of aspirin and clopidogrel in the secondary prevention of ischemic stroke is limited. Therefore, more intensive antiplatelet therapy through a different mechanism of action may be more effective at reducing the risk of recurrent ischemia. The SOCRATES study ${ }^{17}$ investigated whether ticagrelor may be a more effective antiplatelet therapy than aspirin for the prevention of recurrent stroke and cardiovascular events. Ticagrelor is a potent antiplatelet agent that reversibly binds and inhibits the P2Y12 receptor on platelets. However, in conclusion, ticagrelor was not found to be superior to aspirin in reducing the risk of the composite end point, but there were more instances of dyspnea and minor bleeding in the ticagrelor group.

Long-term double platelet inhibition is not generally recommended, but there are recent findings on risk reduction in minor ischemic stroke (stroke with mild, nondisabling neurological deficits) or TIA by short-term treatment with the combination of aspirin and clopidogrel. The POINT study ${ }^{18}$ investigated whether a treatment with aspirin and clopidogrel reduced the rate of recurrent stroke during the first 3 months after a minor stroke or TIA compared with aspirin monotherapy. The results revealed that patients who received a combination of clopidogrel and aspirin had a lower risk of a composite of ischemic stroke, myocardial infarction, or death from ischemic vascular causes. However, those patients had a higher risk of major hemorrhage than patients who received aspirin alone during the 90-day trial period. As a result, the German Stroke Society, in line with recent recommendations published in the British Medical Journal, recommends a short time (10-21 days) combined treatment with aspirin and clopidogrel in these patients. ${ }^{19}$

\section{Oral Anticoagulation}

Patients with ischemic stroke or TIA with proven AF should receive OAC. Additional antithrombotic agents should not be used in secondary prevention in patients with AF, unless there is a cardiological indication. Ischemic strokes based on AF are often severe and surviving patients have a high risk of recurrent stroke. The risk of embolism in patients with $\mathrm{AF}$ depends on the number of additional risk factors. These include heart failure, hypertension, age $>65$ or $>75$ years, diabetes, previous stroke/TIA/systemic embolism, vascular disease, and female gender. In clinical practice, the $\mathrm{CHA}_{2} \mathrm{DS}_{2}-$ VASc score is used for risk estimation. ${ }^{20}$ Before starting an OAC therapy, the risk of bleeding has to be established. Risk factors for the occurrence of bleeding in patients with AF are hypertension, pathological kidney or liver values, stroke, bleeding, an unstable international normalized ratio (INR) in patients on vitamin $\mathrm{K}$ antagonist (VKA) therapy, age $>65$ years, drugs, and alcohol. The HAS-BLED score has been established for estimating the risk of bleeding. ${ }^{21}$
For decades, VKAs have been the only drugs available for OAC in AF. VKA therapy significantly reduces the risk of stroke compared with aspirin or no therapy. ${ }^{22}$ However, the use of VKAs is limited by the narrow therapeutic window, frequent monitoring, and dose adjustments. Nowadays, non-VKA oral anticoagulants (NOACs) are suitable alternatives to VKAs for stroke prevention in AF and are recommended as first-line therapy in patients with nonvalvular AF by the European Society of Cardiology (ESC). ${ }^{23}$ NOACs are as effective as VKAs with a lower risk of life-threatening and intracranial hemorrhage. ${ }^{24-27}$ Compared with VKAs, NOACs do not need regular anticoagulation monitoring. Approved NOACs in AF are the direct factor Xa inhibitors rivaroxaban, apixaban, and edoxaban, and the thrombin inhibitor dabigatran. A specific antidote (idarucizumab) is available for dabigatran. A specific antidote for factor Xa inhibitors (andexanet alfa) has just recently been approved in the European Union. Kidney function should be regularly monitored in AF patients with OAC to allow dose adaptation for those on NOACs. A creatinine clearance $<30 \mathrm{~mL} / \mathrm{min}$ is a contraindication for dabigatran and a clearance $<15 \mathrm{~mL} / \mathrm{min}$ for rivaroxaban, apixaban, and edoxaban.

Besides the classical indication for OAC after stroke, dissection of extracerebral and intracerebral arteries is often considered as an indication for transient OAC. So far, only one randomized study on secondary prevention of ischemic insults after cerebral artery dissection is available. ${ }^{28}$ It has been shown that the recurrence rate of strokes with antiplatelet or anticoagulation therapy did not differ significantly. For decision making, the majority of findings on dissection have been obtained from observational studies. ${ }^{29,30}$ Based on the guidelines of the German Society of Neurology, secondary prevention after cerebral artery dissection initially should be performed with antiplatelet therapy. In the case of a microembolic signal in transcranial ultrasound, multiple recurrent embolic infarcts while on antiplatelet therapy or arterial (pseudo-) occlusion with strong poststenotic flow reduction, anticoagulation therapy may be reasonable. Initial anticoagulation should be performed with low-molecular-weight heparin, followed by oral VKA (target INR: 2-3). So far, NOACs have not been approved for this indication.

In addition, $\mathrm{OAC}$ has been proposed for secondary stroke prevention in patients with ESUS. Two big trials, RE-SPECT ESUS $^{31}$ and NAVIGATE ESUS, ${ }^{32}$ have been performed to evaluate the secondary prevention effects of NOACs in patients with ESUS compared with aspirin. RE-SPECT ESUS investigated the effects of dabigatran compared with aspirin. The major finding was that dabigatran did not significantly prevent recurrence of stroke after ESUS better than aspirin. There was no significantly increased risk of severe bleeding compared with aspirin. ${ }^{31}$ In NAVIGATE ESUS, effectivity of rivaroxaban compared with aspirin was investigated. In summary, rivaroxaban was not superior to aspirin with regard to the prevention of recurrent stroke after ESUS and was associated with a higher risk of bleeding. ${ }^{32}$

\section{Left Atrial Appendage Occlusion}

In patients with $\mathrm{AF}$ and contraindications for long-term OAC, e.g., those with a high risk for bleeding, left atrial appendage 
occlusion may be considered as an alternative therapy option. Left atrial appendage occlusion can be performed during other open-heart surgery or with an interventional catheter-deployed device. Few studies have shown that left atrial appendage occlusion via a catheter-deployed device is noninferior to VKA treatment. ${ }^{33}$ However, the procedure can cause serious complications and further controlled trials are ongoing to inform the best use of these devices as well as comparison of left atrial appendage occluders with NOACs.

\section{Blood Pressure Management}

High blood pressure is a major risk factor for ischemic stroke; various studies on primary prevention of cardiovascular and cerebrovascular events are available. In 2001, the first study on antihypertensive therapy after stroke or TIA revealed that the use of antihypertensive agents in lowering blood pressure leads to a $28 \%$ reduction of a recurrent event. ${ }^{34}$ Further studies investigated the effects of specific antihypertensive medication in secondary prevention after ischemic stroke. ${ }^{35,36}$ The superiority of a specific substance class remains controversial and the primary goal is the achievement of a normal blood pressure. The therapeutic range should be between 120/ $70 \mathrm{~mm} \mathrm{Hg}$ and $140 / 90 \mathrm{~mm} \mathrm{Hg}$ depending on individual comorbidities and adverse effects.

\section{Hypercholesterolemia}

Low-density lipoprotein cholesterol (LDL-C) is a risk marker for ischemic stroke. ${ }^{37}$ Several studies showed that statin therapy reduces the risk of stroke recurrence. While initial studies referred to patients with coronary heart disease (CHD), the SPARCL study ${ }^{38}$ first showed that patients without CHD also benefit from statin therapy. There is no evidence supporting a specific LDL-C target in stroke secondary prevention. According to the guidelines of the German Society of Neurology, the LDL-C target value should be $<100 \mathrm{mg} / \mathrm{dL}$. Another analysis from SPARCL indicates that the protective effect to reduce stroke recurrence and cardiovascular complications is most pronounced when a $50 \%$ reduction of LDL-C is achieved during treatment. ${ }^{39}$ Thus, for stroke patients it may as well be considered reasonable to follow cardiology guidelines in secondary prevention of myocardial infarction that recommend LDL-C target levels of $<70 \mathrm{mg} / \mathrm{dL}$ or a reduction by at least $50 \%$ of the baseline value in patients at very high cardiovascular risk.

Carotid Artery Stenosis and Reperfusion Interventions Symptomatic internal carotid artery stenosis is associated with a high risk of early recurrent stroke and there is clear evidence for the benefit of revascularization treatment over conservative therapy, with moderate benefit for patients with 50 to $69 \%$ stenosis and strong benefit in $\geq 70 \%$ stenosis. ${ }^{40,41}$ Two therapeutic procedures are available: carotid endarterectomy (CEA) and carotid artery angioplasty and stenting (CAS). CEA is a surgical intervention involving the removal of atherosclerotic plaque from the internal carotid artery. CAS is a percutaneous, minimally invasive approach to treating carotid artery stenosis. There is evidence that CAS is of comparable benefit to CEA in patients $<70$ years, while in older patients CAS is associated with a higher risk for death and stroke. ${ }^{42,43}$

\section{Patent Foramen Ovale Closure}

In stroke patients with no other definite cause of stroke, finding of a PFO raises the question whether this may be the cause of stroke and should receive specific treatment. A PFO can be found in approximately $25 \%$ of the healthy population, which makes the finding of a PFO in a stroke patient likely to result from chance. On the other hand, high rates of PFO in younger stroke patients going up to $45 \%$ suggest a causal relationship. Especially in patients younger than 55 years with a PFO, the risk of cryptogenic ischemic insult is increased. Based on three studies from 2017, ${ }^{44-46}$ interventional closure of PFO in patients between 16 and 60 years with a cryptogenic ischemic stroke and PFO with moderate or pronounced rightleft shunt significantly reduced the already low rate of recurrent stroke in these patients. This benefit has to be weighed against a small risk of periprocedural complications including AF. As a consequence, interventional PFO closure should be considered in younger stroke patients with stroke of unknown cause. Results from earlier observational studies as well as recent subgroup analysis of NAVIGATE ESUS suggest that OAC might be superior to antiplatelets for secondary prevention in patients with ESUS and PFO, ${ }^{47}$ but further trials are needed to test this hypothesis.

\section{Secondary Prevention of Stroke Due to Coagulation Disorders}

Hereditary and acquired thrombophilia may be associated with ischemic stroke. Hereditary thrombophilia, such as factor $\mathrm{V}$ Leiden mutation, prothrombin gene mutation G20210A, and deficiencies of protein $\mathrm{C}$, protein $\mathrm{S}$, and antithrombin, is a wellknown risk factor for venous thrombosis, but may also be associated with ischemic stroke. The association of thrombophilia with ischemic stroke is much less strong than with venous thrombosis. However, diagnosis of a significant coagulation disorder in a patient with acute ischemic stroke with no other etiology is usually considered to be an indication for OAC. There are no large clinical trials available to guide recommendations for secondary prevention in patients with stroke and coagulation disorder. Antiplatelet therapy is recommended for patients who are found to have abnormal findings on coagulation testing after initial ischemic stroke or TIA if anticoagulation therapy is not administered. ${ }^{48}$

Antiphospholipid syndrome (APS) presents with venous and arterial thrombosis or one of several specific pregnancy complications in the presence of persistent antiphospholipid antibodies. ${ }^{49}$ An APS should be suspected in patients with ischemic stroke or TIA who have no alternative explanation for the ischemic event and who have other manifestations of the syndrome such as livedo reticularis, obstetric complications, unexplained thrombocytopenia, or prolongation of a coagulation test. There is no general consensus on optimal antithrombotic therapy of patients with ischemic stroke or TIA who have an antiphospholipid antibody. Antiplatelet therapy is often recommended for patients with ischemic stroke or TIA in whom antiphospholipid antibodies are found but who do not meet the criteria for APS. For patients with ischemic stroke or TIA who fulfill the APS criteria, anticoagulation therapy may be reasonable, considering the risk for recurrent thrombotic 
event and bleeding complications. ${ }^{48}$ Currently, VKAs are the standard treatment for OAC in APS. NOACs are increasingly used for OAC in APS, but do not seem to be as effective as VKAs in patients with high-risk APS including those with arterial embolism and stroke. ${ }^{50}$

Most studies and subsequent recommendations on anticoagulation management for coagulation disorders refer to therapy with heparin or VKAs and there is a lack of more recent knowledge on NOACs. Recently, there are new findings for anticoagulation for cancer-associated venous thromboembolism. So far, low-molecular-weight heparin has been the standard therapy. The Hokusai VTE Cancer Study ${ }^{51}$ showed that oral edoxaban was noninferior to subcutaneous dalteparin with respect to the composite outcome of recurrent venous thromboembolism or major bleeding providing first evidence that thromboembolic events due to coagulations disorders may be adequately treated with NOACs.

\section{Future Directions}

The optimization of secondary prevention in stroke is an ongoing process and there are still a lot of areas of uncertainty. Especially pharmacologic therapy is constantly adapted to the results of latest studies. Future developments for prevention of stroke may concern the role of newer platelet inhibitors (prasugrel, ticagrelor) as well as the role of double antiplatelet treatment. The combined (low-dose) anticoagulation and antiplatelet treatment as recently investigated in the COMPASS trial ${ }^{52}$ may also be an interesting treatment approach for secondary prevention in stroke patients with LAA. In addition, the use of NOACs instead of VKAs for indications beyond AF warrants further study.

\section{Conflict of Interest}

G.T. reports personal fees from Acandis, personal fees from Bayer, personal fees from Boehringer Ingelheim, personal fees from Bristol-Myers Squibb/Pfizer, personal fees from Daichi Sankyo, and personal fees from Stryker, outside the submitted work.

\section{References}

1 Collaborators GBDS; GBD 2016 Stroke Collaborators. Global, regional, and national burden of stroke, 1990-2016: a systematic analysis for the Global Burden of Disease Study 2016. Lancet Neurol 2019;18(05):439-458

2 Wiedmann S, Heuschmann PU, Hillmann S, et al; German Stroke Registers Study Group (ADSR). The quality of acute stroke care- an analysis of evidence-based indicators in 260000 patients. Dtsch Arztebl Int 2014;111(45):759-765

3 Fisher CM. Lacunar strokes and infarcts: a review. Neurology 1982;32(08):871-876

4 Barow E, Boutitie F, Cheng B, et al; WAKE-UP Investigators. Functional outcome of intravenous thrombolysis in patients with lacunar infarcts in the WAKE-UP Trial. JAMA Neurol 2019; 76(06):641-649

5 Easton JD, Saver JL, Albers GW, et al; American Heart Association; American Stroke Association Stroke Council; Council on Cardiovascular Surgery and Anesthesia; Council on Cardiovascular Radiology and Intervention; Council on Cardiovascular Nursing; Interdisciplinary Council on Peripheral Vascular Disease. Definition and evaluation of transient ischemic attack: a scientific statement for healthcare professionals from the American Heart Association/ American Stroke Association Stroke Council; Council on Cardiovascular Surgery and Anesthesia; Council on Cardiovascular Radiology and Intervention; Council on Cardiovascular Nursing; and the Interdisciplinary Council on Peripheral Vascular Disease. The American Academy of Neurology affirms the value of this statement as an educational tool for neurologists. Stroke 2009;40(06):2276-2293

6 Adams HP Jr, Bendixen BH, Kappelle LJ, et al. Classification of subtype of acute ischemic stroke. Definitions for use in a multicenter clinical trial. TOAST. Trial of Org 10172 in Acute Stroke Treatment. Stroke 1993;24(01):35-41

7 Lin HJ, Wolf PA, Kelly-Hayes M, et al. Stroke severity in atrial fibrillation. The Framingham Study. Stroke 1996;27(10):1760-1764

8 Nah HW, Kang DW, Kwon SU, Kim JS. Diversity of single small subcortical infarctions according to infarct location and parent artery disease: analysis of indicators for small vessel disease and atherosclerosis. Stroke 2010;41(12):2822-2827

9 Hart RG, Diener HC, Coutts SB, et al; Cryptogenic Stroke/ESUS International Working Group. Embolic strokes of undetermined source: the case for a new clinical construct. Lancet Neurol 2014; 13(04):429-438

10 Thomalla G, Simonsen CZ, Boutitie F, et al; WAKE-UP Investigators. MRI-guided thrombolysis for stroke with unknown time of onset. N Engl J Med 2018;379(07):611-622

11 Ma H, Campbell BCV, Parsons MW, et al; EXTEND Investigators. Thrombolysis guided by perfusion imaging up to 9 hours after onset of stroke. N Engl J Med 2019;380(19):1795-1803

12 Goyal M, Menon BK, van Zwam WH, et al; HERMES collaborators. Endovascular thrombectomy after large-vessel ischaemic stroke: a meta-analysis of individual patient data from five randomised trials. Lancet 2016;387(10029):1723-1731

13 Antithrombotic Trialists' Collaboration. Collaborative meta-analysis of randomised trials of antiplatelet therapy for prevention of death, myocardial infarction, and stroke in high risk patients. BMJ 2002;324(7329):71-86

14 Johnson ES, Lanes SF, Wentworth CE III, Satterfield MH, Abebe BL, Dicker LW. A metaregression analysis of the dose-response effect of aspirin on stroke. Arch Intern Med 1999;159(11):1248-1253

15 van Gijn J, Algra A, Kappelle J, Koudstaal PJ, van Latum A; Dutch TIA Trial Study Group. A comparison of two doses of aspirin $(30 \mathrm{mg}$ vs. $283 \mathrm{mg}$ a day) in patients after a transient ischemic attack or minor ischemic stroke. N Engl J Med 1991;325(18):1261-1266

16 Committee CS; CAPRIE Steering Committee. A randomised, blinded, trial of clopidogrel versus aspirin in patients at risk of ischaemic events (CAPRIE). Lancet 1996;348(9038):1329-1339

17 Johnston SC, Amarenco P, Albers GW, et al; SOCRATES Steering Committee and Investigators. Ticagrelor versus aspirin in acute stroke or transient ischemic attack. N Engl J Med 2016;375(01): $35-43$

18 Johnston SC, Easton JD, Farrant M, et al; Clinical Research Collaboration, Neurological Emergencies Treatment Trials Network, and the POINT Investigators. Clopidogrel and aspirin in acute ischemic stroke and high-risk TIA. N Engl J Med 2018;379(03):215-225

19 Prasad K, Siemieniuk R, Hao Q et al. Dual antiplatelet therapy with aspirin and clopidogrel for acute high risk transient ischaemic attack and minor ischaemic stroke: a clinical practice guideline. BMJ 2018;363:k5130

20 Olesen JB, Lip GY, Hansen ML, et al. Validation of risk stratification schemes for predicting stroke and thromboembolism in patients with atrial fibrillation: nationwide cohort study. BMJ 2011;342:d124

21 Pisters R, Lane DA, Nieuwlaat R, de Vos CB, Crijns HJ, Lip GY. A novel user-friendly score (HAS-BLED) to assess 1-year risk of major bleeding in patients with atrial fibrillation: the Euro Heart Survey. Chest 2010;138(05):1093-1100

22 Hart RG, Pearce LA, Aguilar MI. Meta-analysis: antithrombotic therapy to prevent stroke in patients who have nonvalvular atrial fibrillation. Ann Intern Med 2007;146(12):857-867 
23 Kirchhof P, Benussi S, Kotecha D, et al; ESC Scientific Document Group. 2016 ESC guidelines for the management of atrial fibrillation developed in collaboration with EACTS. Eur Heart J2016;37(38):2893-2962

24 Connolly SJ, Ezekowitz MD, Yusuf S, et al; RE-LY Steering Committee and Investigators. Dabigatran versus warfarin in patients with atrial fibrillation. N Engl J Med 2009;361(12):1139-1151

25 Patel MR, Mahaffey KW, Garg J, et al; ROCKET AF Investigators. Rivaroxaban versus warfarin in nonvalvular atrial fibrillation. N Engl J Med 2011;365(10):883-891

26 Granger CB, Alexander JH, McMurray JJ, et al; ARISTOTLE Committees and Investigators. Apixaban versus warfarin in patients with atrial fibrillation. N Engl J Med 2011;365(11):981-992

27 Giugliano RP, Ruff CT, Braunwald E, et al; ENGAGE AF-TIMI 48 Investigators. Edoxaban versus warfarin in patients with atrial fibrillation. N Engl J Med 2013;369(22):2093-2104

28 Markus HS, Hayter E, Levi C, Feldman A, Venables G, Norris J; CADISS trial investigators. Antiplatelet treatment compared with anticoagulation treatment for cervical artery dissection (CADISS): a randomised trial. Lancet Neurol 2015;14(04):361-367

29 Menon R, Kerry S, Norris JW, Markus HS. Treatment of cervical artery dissection: a systematic review and meta-analysis. J Neurol Neurosurg Psychiatry 2008;79(10):1122-1127

30 Sarikaya H, da Costa BR, Baumgartner RW, et al. Antiplatelets versus anticoagulants for the treatment of cervical artery dissection: Bayesian meta-analysis. PLoS One 2013;8(09):e72697

31 Diener HC, Sacco RL, Easton JD, et al; RE-SPECT ESUS Steering Committee and Investigators. Dabigatran for prevention of stroke after embolic stroke of undetermined source. N Engl J Med 2019; 380(20):1906-1917

32 Harloff A, Schlachetzki F. Rivaroxaban for stroke prevention after embolic stroke of undetermined source. N Engl J Med 2018;379 (10):986-987

33 Holmes DR Jr, Doshi SK, Kar S, et al. Left atrial appendage closure as an alternative to warfarin for stroke prevention in atrial fibrillation: a patient-level meta-analysis.J Am Coll Cardiol 2015;65(24):2614-2623

34 Group PC; PROGRESS Collaborative Group. Randomised trial of a perindopril-based blood-pressure-lowering regimen among 6,105 individuals with previous stroke or transient ischaemic attack. Lancet 2001;358(9287):1033-1041

35 Yusuf S, Diener HC, Sacco RL, et al; PRoFESS Study Group. Telmisartan to prevent recurrent stroke and cardiovascular events. N Engl J Med 2008;359(12):1225-1237

36 Schrader J, Lüders S, Kulschewski A, et al; MOSES Study Group. Morbidity and mortality after stroke, eprosartan compared with nitrendipine for secondary prevention: principal results of a prospective randomized controlled study (MOSES). Stroke 2005;36(06):1218-1226

37 Lewington S, Whitlock G, Clarke R, et al; Prospective Studies Collaboration. Blood cholesterol and vascular mortality by age, sex, and blood pressure: a meta-analysis of individual data from 61 prospective studies with 55,000 vascular deaths. Lancet 2007; 370(9602):1829-1839

38 Amarenco P, Bogousslavsky J, Callahan A III, et al; Stroke Prevention by Aggressive Reduction in Cholesterol Levels (SPARCL) Investigators. High-dose atorvastatin after stroke or transient ischemic attack. N Engl J Med 2006;355(06):549-559

39 Amarenco P, Goldstein LB, Szarek M, et al; SPARCL Investigators. Effects of intense low-density lipoprotein cholesterol reduction in patients with stroke or transient ischemic attack: the Stroke Prevention by Aggressive Reduction in Cholesterol Levels (SPARCL) trial. Stroke 2007;38(12):3198-3204

40 MRC European Carotid Surgery Trial: interim results for symptomatic patients with severe (70-99\%) or with mild (0-29\%) carotid stenosis. European Carotid Surgery Trialists' Collaborative Group. Lancet 1991;337(8752):1235-1243

41 Barnett HJM, Taylor DW, Haynes RB, et al; North American Symptomatic Carotid Endarterectomy Trial Collaborators. Beneficial effect of carotid endarterectomy in symptomatic patients with high-grade carotid stenosis. N Engl J Med 1991;325(07): $445-453$

42 Brott TG, Hobson RW II, Howard G, et al; CREST Investigators. Stenting versus endarterectomy for treatment of carotid-artery stenosis. N Engl J Med 2010;363(01):11-23

43 Voeks JH, Howard G, Roubin GS, et al; CREST Investigators. Age and outcomes after carotid stenting and endarterectomy: the carotid revascularization endarterectomy versus stenting trial. Stroke 2011;42(12):3484-3490

44 Mas JL, Derumeaux G, Guillon B, et al; CLOSE Investigators. Patent foramen ovale closure or anticoagulation vs. antiplatelets after stroke. N Engl J Med 2017;377(11):1011-1021

45 Kuijpers T, Spencer FA, Siemieniuk RAC, et al. Patent foramen ovale closure, antiplatelet therapy or anticoagulation therapy alone for management of cryptogenic stroke? A clinical practice guideline. BMJ 2018;362:k2515

46 Saver JL, Carroll JD, Thaler DE, et al; RESPECT Investigators. Longterm outcomes of patent foramen ovale closure or medical therapy after stroke. N Engl J Med 2017;377(11):1022-1032

47 Kasner SE, Swaminathan B, Lavados P, et al; NAVIGATE ESUS Investigators. Rivaroxaban or aspirin for patent foramen ovale and embolic stroke of undetermined source: a prespecified subgroup analysis from the NAVIGATE ESUS trial. Lancet Neurol 2018;17(12):1053-1060

48 Kernan WN, Ovbiagele B, Black HR, et al; American Heart Association Stroke Council, Council on Cardiovascular and Stroke Nursing, Council on Clinical Cardiology, and Council on Peripheral Vascular Disease. Guidelines for the prevention of stroke in patients with stroke and transient ischemic attack: a guideline for healthcare professionals from the American Heart Association/American Stroke Association. Stroke 2014;45(07): 2160-2236

49 Miyakis S, Lockshin MD, Atsumi T, et al. International consensus statement on an update of the classification criteria for definite antiphospholipid syndrome (APS). J Thromb Haemost 2006;4 (02):295-306

50 Bauersachs R, Schellong S, Stücker M, et al. Therapie des Antiphospholipid-Syndroms (APS) mit DOAKs. Hamostaseologie 2019;39(03):298-300

51 Raskob GE, van Es N, Verhamme P, et al; Hokusai VTE Cancer Investigators. Edoxaban for the treatment of cancer-associated venous thromboembolism. N Engl J Med 2018;378(07): 615-624

52 Anand SS, Bosch J, Eikelboom JW, et al; COMPASS Investigators. Rivaroxaban with or without aspirin in patients with stable peripheral or carotid artery disease: an international, randomised, double-blind, placebo-controlled trial. Lancet 2018;391 (10117):219-229 